\title{
Awareness of orthodontic treatment among parents of children 5-17 years of age in Kanchipuram district - A
}

\author{
survey \\ Thirunavukkarasu R ${ }^{1}$, Muralidharan $D^{1}$, Nirupama $C^{1}$, Prashanth $C^{1}$, Gaurav Gupta ${ }^{1}$, Karthikeyan $E^{2}$ and Sakthisri $V^{3}$ \\ ${ }^{1}$ Department of Orthodontics, Karpaga Vinayaga institute of dental sciences, Tamil Nadu, India \\ ${ }^{2}$ Department of Community Medicine, Karpaga Vinayaga institute of Medical Sciences, Tamil Nadu, India \\ ${ }^{3}$ Internship at Karpaga Vinayaga institute of dental sciences, Tamil Nadu, India
}

\begin{abstract}
Aim: To assess the awareness of Orthodontic treatment among parents of children 5-17 years of age in Kanchipuram District.

Materials and Methods: A cross sectional survey was conducted in randomly selected five private schools in Kanchipuram district. Nearly 2000 parents of children 5-17 years of age among the five selected schools were participated in the survey. A self-administered structured questionnaire was given to the children to be filled by their parents. The parent's awareness and knowledge were assessed after the data were analyzed with chi-square test. Results: About $90 \%$ parents are aware of the specialty Orthodontics. To achieve good set of dentitions $76.5 \%$ parents, consider orthodontic treatment is essential.51.2\% parents consider oral habits like thumb sucking has one of the reasons for malocclusion. $57.6 \%$ parents did not know that the orthodontic treatment can be started even during the growth period of their children.
\end{abstract}

Conclusion: The study showed presence of average awareness and knowledge among parents towards orthodontic problems and its treatment.

\section{Introduction}

Awareness is a state or quality of being aware of something [1]. Children and Adolescents are the major category of target group for seeking orthodontic treatment. Parents and guardians are the most important motivating factors to influence the need of orthodontic treatment among children and adolescents. School teachers are another group with a close relationship with children and adolescents, and students are widely influenced by them [2]. Majority of the parents still do not considered malocclusion as a dental problem [3]. The funding of orthodontic treatment, socioeconomic status, ethnic origin, availability of limited resources, literacy rate, lack of knowledge on malocclusion plays a major role in determining the parent's perception and attitude to seek orthodontic care for their children. Parents noticing that their children being teased by their peers, realize the need of orthodontic treatment. Psychosocial attractiveness research has demonstrated that persons with increased public self-consciousness are rated as more attractive by others [4]. The parents of girl child are slightly aware and are concerned more about their appearance. The objectives of the study are:

1. To evaluate the awareness among parents towards orthodontic treatment.

2. To determine whether there is an association between parental perceptions towards their child's orthodontic care.

3. To explore the knowledge of parents regarding the orthodontic problems and its treatment.

\section{Materials and methods}

A Cross-sectional study was conducted among parents of the school children aged 5 to 17 years to assess the knowledge and awareness about orthodontic treatment. Ethical clearance was obtained from the ethical committee of Karpaga Vinayaga Institute of Medical Sciences to conduct the survey. From the list of schools in Kanchipuram district, five private schools were randomly selected after obtaining permission from the DEO of Kanchipuram district. The school authorities were approached and explained about the nature of the study and permission was obtained. Written informed consent was obtained from the participants. Out of 2000 parents, only 1951 parents of the children among the five selected schools participated in the survey. 49 parents were not willing to participate in the survey. The survey was conducted from January 2019 to March 2019. A self-administered structured questionnaire consisting of two segments was presented to the parents by their children. First segment consists of six multiple choice questions related to parents awareness on orthodontic treatment. Second segment of six multiple choice questions aimed to assess the knowledge of orthodontic treatment. The data collected were tabulated on a Microsoft Excel computer program and descriptive statistics using chi-square test was carried out. The statistical analysis was performed using SPSS software V.16.0.

\section{Demographic data:}

Name: Place:

Age and Sex: Date:

${ }^{*}$ Correspondence to: $\mathrm{R}$ Thirunavukkarasu, Professor, Department of Orthodontics, Karpaga Vinayaga Institute of Dental Sciences, Tamil Nadu, India, E-mail: mural_ramu06@yahoo.co.in

Key words: awareness, knowledge, parents, orthodontic treatment

Received: July 02, 2019; Accepted: July 18, 2019; Published: July 22, 2019 
Monthly income:

\section{Questionnaire:}

1. Do you know there is a specialty in dentistry called ORTHODONTICS? (Y/N/Don't know)

2. Why do you think you need to put braces (orthodontic treatment)?

(A. Good set of teeth B. Beautification C. Other reasons D. Don't know)

3. Who will you first go to consult regarding braces (orthodontic treatment?

(A. General physician/pediatrician B. General dentist C. Orthodontist D. Don't know)

4. In which situation you think braces (orthodontic treatment) is necessary?

(A. To avoid your child being teased B. Marriage C. Job D. Others E. Don't know)

5. Do you know the duration of braces treatment? (Y/N/Don't know)

6. Do you know the cost of braces treatment? (Y/N/Don't know)

7. Which age should you consult regarding wearing braces (orthodontic) treatment?

(A. immediately after milk tooth eruption B. Aftercompletioin of permanent teeth eruption C. Only after permanent tooth starts erupting D. Don't know)

8. What is the reason for malposed teeth?

(A. Heriditary B. Oral Habits C. Growth deficiency D. Other reasons E. Don't know)

9. Of the following condition which do you think needs braces treatment?

(A. Smile problem B. Irregularly arranged teeth C. Gap between teeth D. Jaw mismatch E. Other reasons F. Don't know)

10. Do you know, there is an option to treat children with during their growth period? (Y/N/Don't know)

11. Are you aware of need for extraction during braces treatment? (Y/N/ Don't know)

12. Do you know, for some conditions surgery is needed to correct the teeth? (Y/N/Don't know)

\section{Results}

\section{Age and gender wise distribution of parents:}

Of 1951 participants, majority of parents belongs to age group of $33-40$ years $(52.7 \%)$ followed by $24-32$ years $(31.58 \%)$. Among them, $52.12 \%$ were female participants and $47.8 \%$ were male participants.

Distribution of parents based on Socio-economic status of parents can be identified by their monthly income and they are grouped based on Modified Kuppusamy Scaling Criteria [5]. Above 90\% parents were categorized under upper and lower middle class.

Among 1951 participants, 89.4\% were aware of Orthodontics as a branch indentistry. To achieve good set of dentition $76.5 \%$ parents consider orthodontic treatment is essential. $48 \%$ of parents preferred to consult their general dentist whether orthodontic treatment is needed for their children. Children's are being teased is the main reason for opting an orthodontic treatment by $73.09 \%$ of parents. Nearly $75 \%$ of parents were unaware of the cost and duration of orthodontic treatment.

$62.4 \%$ parents thought that to undergo orthodontic treatment the eruption of permanent teeth is necessary. About $51.2 \%$ parents consider oral habits like thumb sucking will also be a reason for malocclusion. Other reasons like hereditary, growth deficiency were also considered as one of the etiology for malocclusion by the parents. $57.6 \%$ parents did not know that the orthodontic treatment can be started even during the growth period of their children. For orthodontic treatment, $47.3 \%$ parents are aware that extraction will be required and $55.9 \%$ parents felt that surgery is also one of the treatment options. Table 1 shows the distribution of answers based on age and sex of parents.

\section{Discussion}

\section{Response of parents regarding awareness and knowledge of} orthodontic treatment:

According to Oshagh, et al. parents awareness of children's orthodontic problems can be increased by means of information leaflets [6]. In our study, half of the parents don't have aware towards orthodontics and they consult their general dental first for the orthodontic problems. This could be due to the lack of information about orthodontics in the media or any other type of it, which did not differ much between the genders and other differences, might be attributed to lack of knowledge about orthodontics among the parents. Similar results have been reported by the household study conducted by Dr. Rajvinder Singh, et al. where majority of male (146) and female (136) participant had responded that they did not have any knowledge about orthodontist [7]. The importance of an orthodontic information package towards the awareness was emphasized by Anderson, et al. [8]

According to American Association of Orthodontists, early orthodontic correction can be started as early as 7 yrs. of age. Most of growth correction is done using myofunctional appliance during mixed dentition period. Similar results reported in our study, as more than half of the parents wants to consult their dentist/orthodontist regarding the first orthodontic visit of their children only after the permanent tooth starts erupting. In our study, 51.6\% of parents have no idea that orthodontic treatment carried out during growth period will be faster and easier to achieve esthetically pleasing profile.

Pabari, et al. stated that improving smile esthetic found to be the prime motivating factor for the patient [9]. Parents who noticed the irregular teeth and its consequences in others children are more aware to motivate their children to undergo orthodontic treatment to achieve good dentition and esthetics. Tung, et al. reported in their study that $75 \%$ of the parents were dissatisfied with their children's appearance of teeth and $54 \%$ of the parents wanted their children to look pretty [10]. This is similar to our study where $76.5 \%$ parents concerned about the good set of dentition and only $18.75 \%$ parents were concerned about esthetics as a need to undergo orthodontic treatment.

In general, the public equates good dental appearance with success in a variety of pursuits [11].73.1\% Parents who are more concerned about their children's self-esteem realizes the need for orthodontic treatment so that their children won't be get teased by their peers. Better dental and facial esthetics play an essential role in finding better jobs and social contacts [12]. The duration of orthodontic treatment may vary according to the type of malocclusion of the children. Thus, it is not very strange that the parents may not know about the duration of 
Table 1. showing results of Questions from 1-12

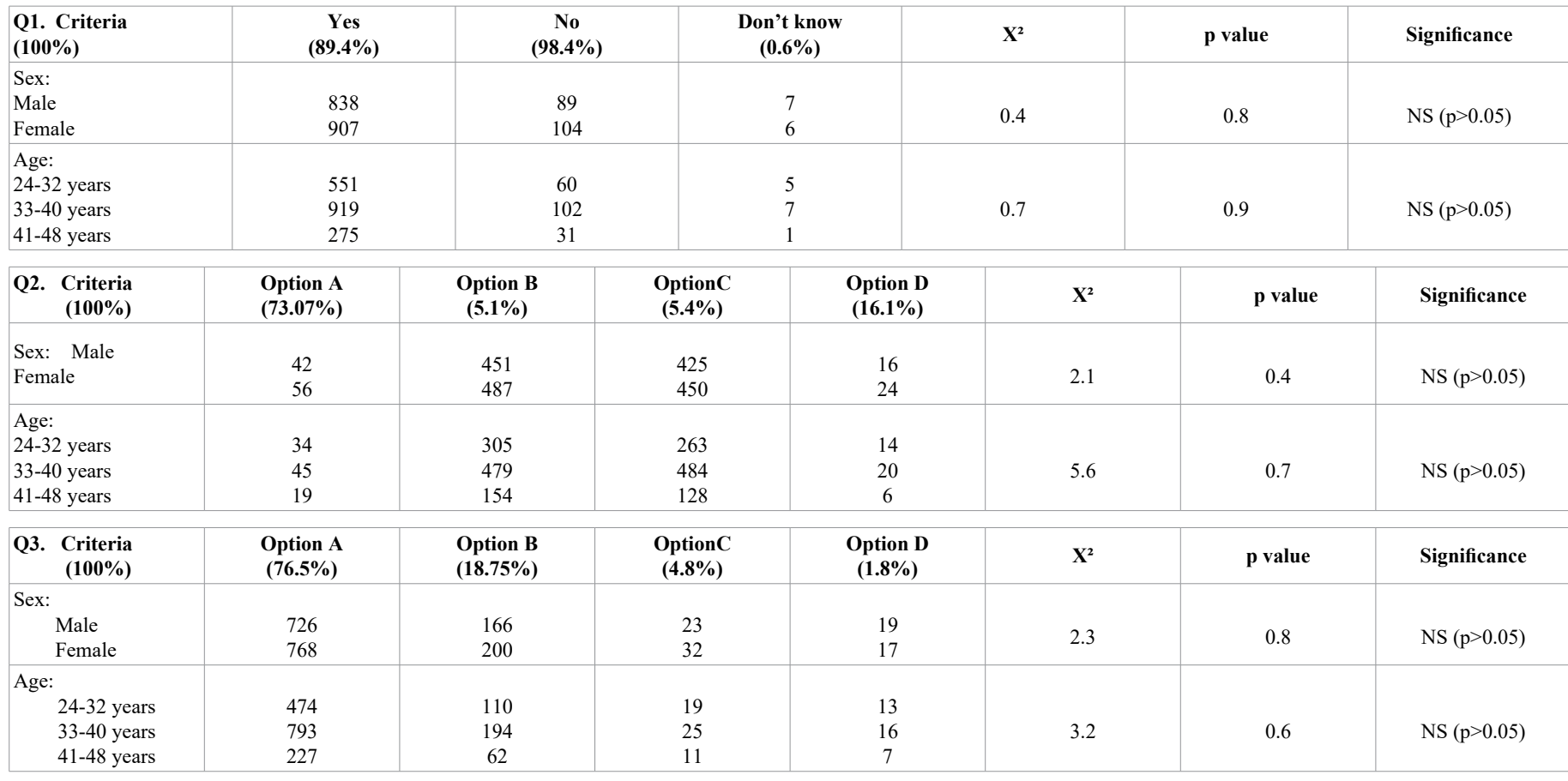

\begin{tabular}{|c|c|c|c|c|c|c|}
\hline $\begin{array}{l}\text { Q4. Criteria } \\
(100 \%)\end{array}$ & $\begin{array}{c}\text { Yes } \\
(23.6 \%)\end{array}$ & $\begin{array}{c}\text { No } \\
(75.5 \%)\end{array}$ & $\begin{array}{c}\text { Don't know } \\
(1.8 \%)\end{array}$ & $\mathbf{X}^{2}$ & p value & Significance \\
\hline $\begin{array}{l}\text { Sex: } \\
\text { Male } \\
\text { Female }\end{array}$ & $\begin{array}{l}218 \\
243\end{array}$ & $\begin{array}{l}701 \\
753\end{array}$ & $\begin{array}{l}15 \\
21\end{array}$ & 0.6 & 0.7 & NS $(p>0.05)$ \\
\hline $\begin{array}{l}\text { Age: } \\
24-32 \text { years } \\
33-40 \text { years } \\
41-48 \text { years }\end{array}$ & $\begin{array}{c}139 \\
232 \\
90\end{array}$ & $\begin{array}{l}465 \\
775 \\
214\end{array}$ & $\begin{array}{c}12 \\
21 \\
3\end{array}$ & 7.6 & 0.4 & NS $(p>0.05)$ \\
\hline
\end{tabular}

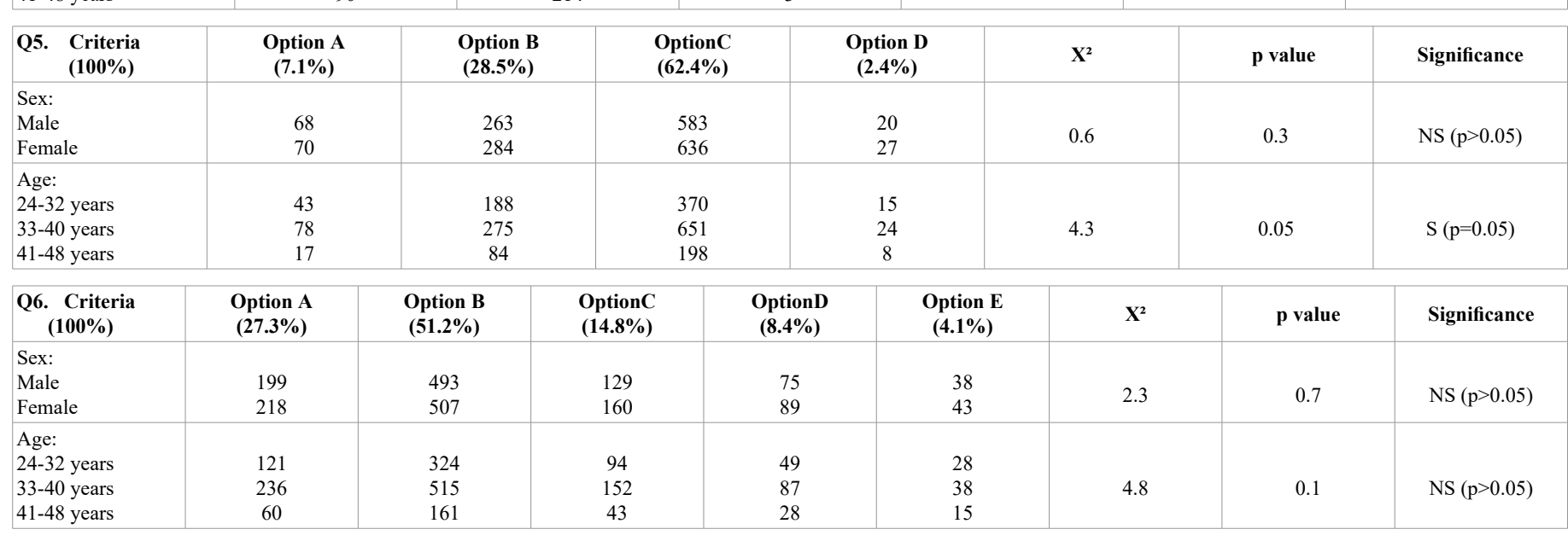

\begin{tabular}{|c|c|c|c|c|c|c|}
\hline $\begin{array}{l}\text { Q7. Criteria } \\
(\mathbf{1 0 0 \% )}\end{array}$ & $\begin{array}{c}\text { Yes } \\
(22.1 \%)\end{array}$ & $\begin{array}{c}\text { No } \\
(75.9 \%)\end{array}$ & $\begin{array}{c}\text { Don't Know } \\
(1.8 \%)\end{array}$ & $\mathbf{X}^{2}$ & p value & Significance \\
\hline $\begin{array}{l}\text { Sex: } \\
\text { Male } \\
\text { Female }\end{array}$ & $\begin{array}{l}213 \\
220\end{array}$ & $\begin{array}{l}705 \\
776\end{array}$ & $\begin{array}{l}16 \\
21\end{array}$ & 0.6 & 0.7 & NS $(p>0.05)$ \\
\hline $\begin{array}{l}\text { Age: } \\
24-32 \text { years } \\
33-40 \text { years } \\
41-48 \text { years }\end{array}$ & $\begin{array}{c}135 \\
217 \\
81\end{array}$ & $\begin{array}{l}469 \\
791 \\
221\end{array}$ & $\begin{array}{c}12 \\
20 \\
5\end{array}$ & 3.9 & 0.4 & NS $(p>0.05)$ \\
\hline
\end{tabular}




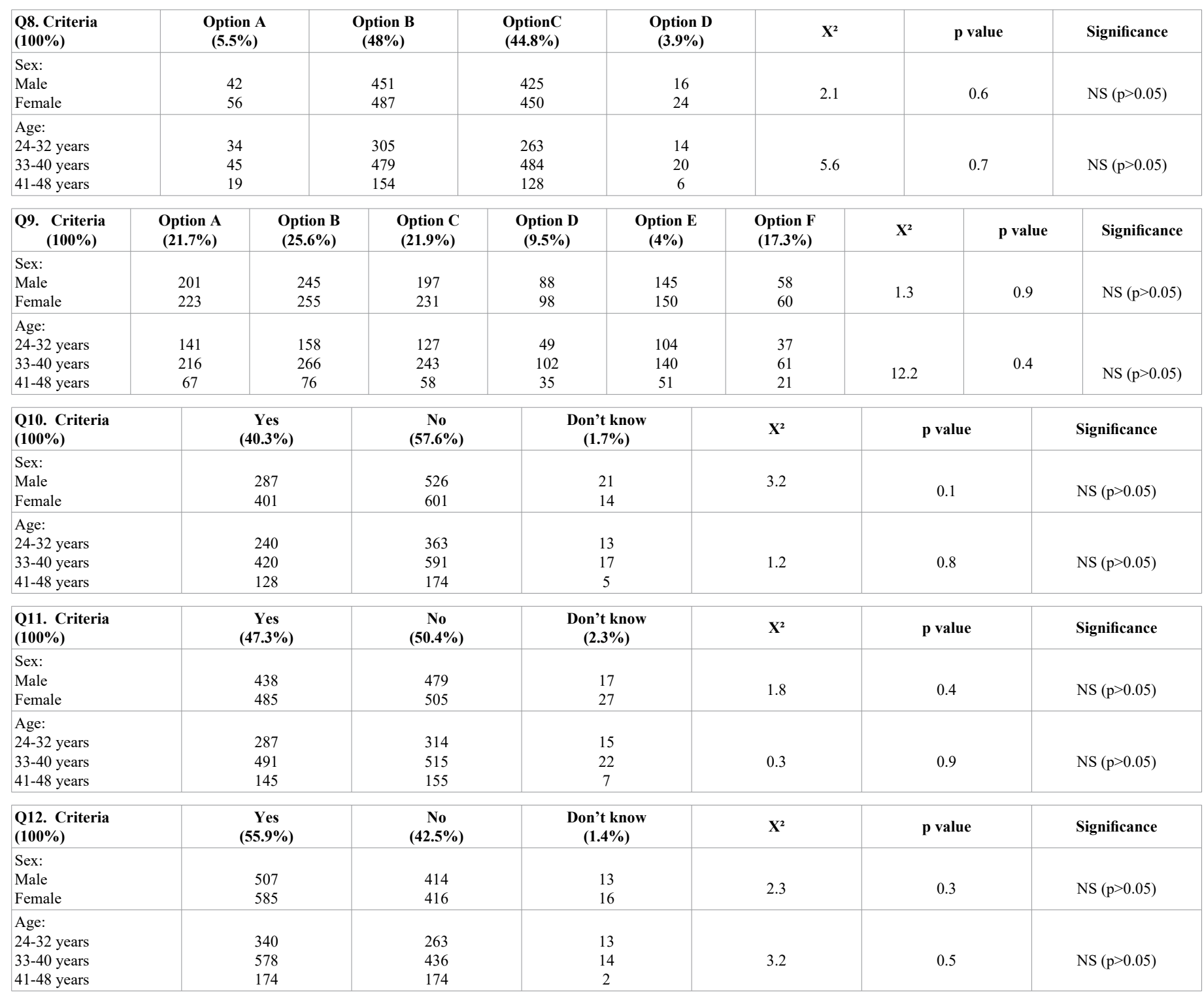

the treatment. Only $22.1 \%$ parents are aware of duration of orthodontic treatment. $75.5 \%$ of parents had no idea on cost of orthodontic treatment. The socio-economic situation also plays a major role as parents financial situation also determine the need for treatment of malocclusion and at times irregularities of teeth is also not considered abnormal [4].

Harris and Smith found that genetic contribution to occlusal variation is quite low [13]. 51.2\% parents believed that oral habits of their children like thumb sucking will results in malocclusion. Parents according to their child's malocclusion consider various conditions like irregularly arranged teeth, gap between the teeth, jaw mismatch, smile problems, proclined teeth etc., to require orthodontic treatment.

The anxious level of parents seeking orthodontic treatment for their children is being described that as $55.9 \%$ parents thought that there may be need for major surgeries which they cannot afford and also not willing to do. Whereas only $50.4 \%$ parents are aware that extraction of teeth is indicated for correction of teeth. The difference in this percentage shows that the parents themselves consider that to correct the teeth major surgeries may be required which also be a cause for postponing the treatment.

\section{Conclusion}

Our study concludes that,

1. The awareness among parents towards orthodontic treatment is found to be average.

2. Parental perception towards their child's orthodontic care is more positive.

3. More than half of the parents are knowledgeable regarding orthodontic problems and its treatments.

\section{Conflicts of interest}

There is no conflict of interest for this manuscript submitted.

\section{References}

1. Mahajan BK (1991) Social environment. Textbook of Preventive and Social medicine. ( $1^{\text {st }}$ Edn) New Delhi; Jaypee Brothers Medical Publishers (P) Ltd pp. 82-87. 
2. Rafighi A, Foroughi Moghaddam S, Alizadeh M, Sharifzadeh H (2012) Awareness of orthodontic treatment among schoolteachers of two cities in Iran. J Dent Res Dent Clin Dent Prospects 6: 25-28. [Crossref]

3. Siddegowda R (2013) Awareness of Orthodontic treatment in school children of Karnataka state. A survey IOSR-JAP 4: 2278-4861.

4. Ulrich Kliges, Aladar Bruckner, Andrej Zentner (2004) Dental esthetics, selfawareness, oral health related quality of life in young adults. Euro J Orthod 26: 507514. [Crossref]

5. Kuppuswamy B (1981) Manual of socioeconomic status (Urban). ( $1^{\text {st }}$ Edn), Delhi: Manasayan pp. 66-72.

6. Oshagh M, Danaei SM, Ghahremani Y, Pujuhi N, Boushehri SG (2011) Impact of an educationalleaflets on parents knowledge and awareness of children orthodontic problems in Shiraz. East Mediterr Health J 17: 121-125. [Crossref]

7. JoharRajvinder S, Hanmanth RG, Shridhar M, Piyush K, DrAkhilesh B, et al. (2014) An Orthodontist Day out- Awareness \& Desire for Orthodontic treatment in School Children and their Parents- A Household Survey. J Pre Clin Dent Res 1: 19-24.
8. Anderson MA, Freer TJ (2005) An orthodontic information package designed to increase patient awareness. Aust Orthod J 21: 11-18. [Crossref]

9. Pabari S, Moles DR, Cunningham SJ (2011) Assessment of motivation and psychological characteristics of adult orthodontic patients. Am J Orthod Dentofacial Orthop 140: 263-272. [Crossref]

10. Tung AW, Kiyak HA (1998) Psychological influences on the timing of orthodontic treatment. Am J Orthod Dentofacial Orthop 113: 29-39. [Crossref]

11. Samuels J, Proshek J (1973) The importance of dental appearance in a prestige hierarchy of occupations (IADR Abstr 273). J Dent Res SZ (Specia1 Issue).

12. Gosney MB (1986) An investigation into some of factors influencing the design for orthodontic treatment. Br J Orthod 13: 87-94. [Crossref]

13. Harris EF, Smith RJ (1980) A study of occlusion and arch widths in families. American Journal of Orthodontics 78: 155-163.

Copyright: (C2019 Thirunavukkarasu R. This is an open-access article distributed under the terms of the Creative Commons Attribution License, which permits unrestricted use, distribution, and reproduction in any medium, provided the original author and source are credited. 